\title{
The effect of location on the distribution of withdrawals from selected ATMs of the "Euronet" network
}

\section{Introduction}

The rapid changes in payment systems and their development started in the early 1980s. Earlier, payment systems were quite simple. They consisted of cash, checks, and bank and postal giros. After the introduction of debit and credit cards, the payment system totally changed. This is also reflected in the way cash was obtained. Until the early 1980s, cash was distributed via banks (i.e., bank offices); but in the 1980s, Automated Teller Machines (ATMs) and cash dispensers replaced many bank offices in cash-liquidity services (see Gurgul, Suder 2012, 2013).

The number of installed ATMs has increased steadily over the last two decades of the Twentieth Century. In contrast to this observation, the number of bank offices has significantly decreased. However, in some well-developed countries, this trade-off process stopped in recent years, and one can now notice a downward trend of ATM withdrawals despite the increase in real terms of the amount of cash observed in recent years.

One of the major issues related to ATM-network management is the issue of forecasting the size of withdrawals. An accurate prediction provides the opportunity to load an ATM with an adequate amount of cash. The desired amount of money cannot be too large, since cash should not be unnecessarily frozen. It also cannot be too small, as it must ensure proper functioning of the ATM until the next-scheduled loading. From a practical point of view, even proper forecasting of withdrawals on particular days of the week may turn out to be insufficient.

* Professor, AGH University of Science and Technology.

** MSc, AGH University of Science and Technology. 
The process of an operator loading cash to an ATM takes place at various times of the day. This means that, in order to determine the amount of money to be loaded, it is required to gain not only the information on the amount of money to be withdrawn over the next few days, but also information regarding the time of day that the loading will take place as well as the distribution of withdrawals throughout the day. The average time between reloading an ATM is usually 3-4 days. The loaded amount of money is usually close to 200-300,000 PLN. Thus, if the amount of predicted withdrawals at a specific ATM equals 300,000 PLN over the period of next three days (e.g., Monday, Tuesday, and Wednesday) and the loading is to take place on Monday, the information about what time the loading should be performed is of special importance. If the loading takes place in the morning, then this amount of money may turn out to be sufficient. If the loading, however, is performed in the evening, the amount of money may turn to be too high (by nearly 100,000 PLN). As the ATM loading team can deliver the cash at any time during the day, information about the proper time of loading as well as knowledge of the time distribution of withdrawals is required to optimize the money-loading process. The first problem (time of loading) is an issue related to the process of organization and requires an appropriate plan of cash convoying. The answer to the second question (distribution) requires a deep analysis of the properties of withdrawals from each ATM for each day of the week.

The goal of this study is to determine the distribution of withdrawals from analyzed ATMs throughout the day, and to examine whether there is a correlation between the distribution of withdrawals from ATMs operating in similar locations. Another important issue is related to the question of whether the distribution of withdrawals depends on ATM location; i.e., ATMs operating in similar locations are characterized by a similar distribution of withdrawals. The last research question is devoted to the establishment of a theoretical distribution that could be used to report the size of withdrawals from the ATMs throughout the day.

The remaining part of the paper is organized as follows. Section 2 presents a literature overview. The following section shows the data and respective descriptive statistics. The fourth section refers to distributions and empirical results for particular locations. The fifth section concludes the paper.

\section{Literature overview}

The first automatic teller machine (ATM) was installed by Barclays Bank at its Enfield, UK branch on 27 June, 1967. However, there are some problems determining who first invented the ATM. The invention of ATM was based on the 
idea of a "dispensing" machine. This idea supposes that this machine dispense an item of the customer's choice in return for money deposited. Based on this idea, the customer inserted a "token" (in the form of a hole-punched voucher) to receive money. This token was purchased by the customer at the bank office. The voucher was inserted in one drawer, and the ATM dispensed a £10 note in another drawer. One precondition was for the customer to enter of the correct verification code. The technological invention was matching the code of the hole-punched voucher with the code entered by the customer. This technology was replaced by the magnetic strip in 1969. Finally, the first fully-automatic ATM was introduced by Docutelin in 1971. It was called the "Total Teller". The first network of ATMs (called TABS 500, implemented in 1978) was developed and enforced by Diebold in a number of locations in the United States. Due to connection of the ATM to the mainframe computer - and subsequent networks a huge rise in the number of transactions was noticed. Also, customer demand for ATMs exploded.

For example, in 2003, there was one ATM for every 1135 people in the United Kingdom (UK). The installed ATMs dispensed $\$ 140$ billion via 2.4 billion transactions. This allows us to assume about 40 billion visits per year. The average withdrawal amounted to $\$ 60.00$ per transaction. In spite of the rapid development of our cash dispensing system, the ATM still remains the most important mode of accessing cash. Other modes include withdrawals at a post office counter and a supermarket teller (referred to as a "cash back"). However, these ways have been replaced more and more by ATMs withdrawals.

As we saw, the ATM will remain a very important mode in the near future. In spite of its great importance, this mode has yet to receive significant attention in the academic literature, especially from researchers who are concerned with the social study of technology. The first contributions about ATMs focused on some studies on ATM users (Adams, Thiehen 1991; Gill 1996; Hatta, Iiyama 1991; Johnson, Coventry 2001; Rogers et al. 1997; Thatcher et al. 2005; Van der Heiden 1990). These studies concentrated on the attributes of the technology. The important topic was how particular users interact, or might interact, with them. In these studies, the ATM is mostly handled as a product of technical design decisions. They serve certain human needs and demands.

However, in many developing countries, many individuals are unable to access the ATM network due to total or functional illiteracy, or due to the overwhelming physical distance that they have to travel in order to access the nearest ATM.

In spite of these problems, overall use of doing business electronically either by ATM, phone, fax, direct deposit and payment, other electronic transfer, and/or computer - has continued to increase in developed countries over the last decade. 
In 2007, about 93 percent of US households used an electronic method as one of their main ways of doing business. One can observe that differences in income, education, and age have become less pronounced. According to L. Mester (2009), differences in the popularity of ATMs and debit card usage across age groups remain. Almost 86 percent of those under 30 years old use ATM or debit cards as one of their main ways of conducting business, while only around 50 percent of people over 60 years old use them. Still, the usage by those over 60 has more than tripled since 1995.

A time series reflects daily business activity. It is usually collected on a daily, monthly, or quarterly basis (or some other period). In the late seventies, W.S. Cleveland and S.J. Devlin (1980) and L.M. Liu (1980) noted that withdrawal activity depends on the number of working days as well as calendar (seasonal) effects.

Besides the number of working days, the day of the week, or the week of the month, other calendar effects such as public holidays or religious events may also affect a time series. Moreover, ATM withdrawals may be affected by additional factors such as paydays or seasonal demand. They are also subject to trends and generally follow weekly, monthly, or annual cycles. This calendar effect is mentioned in a paper by R. Simutis et $a l$. (2008) and is related to the logistical management of the ATM system.

D.J. Hand and G. Blunt (2001) conducted one of the earliest statistical analyses about credit card transactions. Interest in establishing a relationship between ATMs and the demand for cash is reflected in E. Amromin and S. Chakravorti (2007), W.C. Boeschoten (1998), and H. Snellman and M. Viren (2009).

Amromin and Chakravorti (2007) applied a linear regression and conducted a panel-data analysis in order to compare countries. The authors focused on the growth of debit card point-of-sale transactions. W.C. Boeschoten (1998) and H. Snellman and M. Viren (2009) derived their conclusions on the basis of models of individual customer behavior. W.C. Boeschoten (1998), based on Dutch consumer data, assumed that individuals maintain a certain level of cash that is used at a constant rate. Individuals replenish their stock when it falls below a certain threshold. The authors detected that ATM users typically had a lower stock than non-users because the cost of obtaining cash was lower. H. Snellman and M. Viren (2009) tried to model in a deterministic-optimization framework the relationship between the cost of cash withdrawals and the number of ATMs, where costs were assumed to be proportional to distance from ATMs.

D.F. Findley and B.C. Monsell (2009) and D.F. Findley et al. (1998) stressed that modeling of calendar effects is of great importance, because it improves the features of the respective time series and leads to better results in forecasting.

W.S. Cleveland and S.J. Devlin (1980) established, on the basis of a large sample, a distribution of withdrawal frequencies for a monthly time series. The authors detected the main frequencies for these time series. D.F. Findley and 
R.J. Soukup $(1999,2000,2001)$ tried to find distributions in samples in order to check the effect of day. T.S. McElroy and S. Holland (2005) defined a nonparametric test for distribution of maxima in samples.

Brentnall et al. $(2008,2010)$ applied a multinomial distribution for the distribution of cash amounts in their contributions. Random effects were modeled by a Dirichlet distribution or the empirical distribution of individual maximum likelihood. The contributors demonstrated that the empirical distribution of random effects performed well. The reason was that there were a large number of individual accounts.

Taking into account the results reviewed in this section, we will formulate research hypotheses in the next part of this paper.

\section{Main conjectures}

The strategy and rules of replenishing cash in ATMs should take into account both the needs of customers (demand on money from ATMs) and the costs of ATM operators. The loading of cash to an ATM is conducted at different times of the day, and the size and time of withdrawals are not known. Thus, it is an important task from both a theoretical and practical point of view to determine a distribution law of daily withdrawals from ATMs and factors that determine distribution.

Based on visual inspection of the data, we formulate the following hypothesis:

Conjecture 1. Daily distributions of withdrawals are statistically invariant in respect to a particular day.

Taking into account that withdrawals from ATMs operating in similar locations exhibit similar patterns, we hypothesize:

Conjecture 2. There is a similar distribution of daily withdrawals from ATMs operating in similar locations.

Since we take into account ATMs in different locations, it would be interesting to find a typical distribution law for a specific location. Taking into account the results of visual inspection of the dataset, we formulate the next.

Conjecture 3. The structure of daily withdrawals from ATMs operating in shopping centers, bank branches, shops, and hypermarkets is similar and can be well-approximated by logistic distribution.

ATMs in gas stations are open 24 hours. Therefore we hypothesize that uniform distribution fits withdrawal data better than other distributions.

Conjecture 4. Uniform distribution is superior when describing withdrawals from ATMs located in petrol stations.

In the next section, we will describe and conduct a preliminary analysis of the dataset properties. 


\section{Dataset and its properties}

The dataset used in the empirical research contains the values of withdrawals from 44 ATMs owned and operated by the Euronet company. This company is currently the largest of a group of 28 operators of ATM networks in Poland. The company holds nearly $25 \%$ of the overall ATM networks in Poland and currently possesses almost 3,000 ATMs.

In the analysis, the detailed information on all withdrawals from every analyzed ATM in the year 2011 was used. Because the amounts of daily withdrawals from individual ATMs differ significantly, the empirical analysis was based on comparing the values describing the shares of overall daily withdrawals from each ATM, not the daily withdrawals themselves. Such an approach will allow us to compare the structure of withdrawals from ATMs operating in different locations, for which the daily sums of withdrawals differ significantly.

For each ATM, three characteristics have been analyzed: the province in which the ATM operates, the population of the town/city the ATM operates in, and the type of location. The Euronet company considers 15 types of location: airport, bank branch, bus station, shopping center, industrial plant, hypermarket, hotel, gas station, railway station, housing estate, restaurant, shop, shopping center, transportation hub, and other.

In addition, the locations were assigned to one of the categories, depending on the number of inhabitants of the city/town/village in which the ATM is located (rounded to the nearest thousand):

- 0-20 thousand - villages and small towns - Category I;

- 21-50 thousand - cities of average size - Category II;

- 51-100 thousand - big cities - Category III;

- 101-200 thousand - cities of a very large size (e.g., Rzeszow) - Category IV;

- Over 200 thousand - metropolises (e.g., Krakow) - Category V.

In subsequent parts of this paper, this characteristic will be referred to as the population category.

All of the mentioned characteristics will allow an examination of whether the location of an ATM has a significant impact on the distribution of withdrawals throughout the day.

The empirical analysis was performed only in the case of those locations which comprised of at least 10 ATMs. In the case of each population category, we focused on ATMs that operate in locations characterized by relatively different numbers of inhabitants (one or two ATMs in each type of location). In general, we selected those ATMs that are reloaded approximately every three days. From 
The effect of location on the distribution of withdrawals from selected ATMs...

a practical point of view, knowledge of the distribution of withdrawals throughout the day in the case of such ATMs is crucial. Table 1 shows basic information about the locations of the selected ATMs.

Table 1

Locations of the selected ATMs

\begin{tabular}{|c|c|c|c|c|c|}
\hline Type of location & I & II & III & IV & V \\
\hline Bank Branch & $\begin{array}{c}\text { Limanowa } \\
\text { Wadowice }\end{array}$ & $\begin{array}{c}\text { Chrzanów } \\
\text { Jasło }\end{array}$ & $\begin{array}{c}\text { Nowy Sącz } \\
\text { Przemyśl }\end{array}$ & $\begin{array}{c}\text { Tarnów } \\
\text { Rzeszów }\end{array}$ & $\begin{array}{c}\text { Kraków } \\
\text { Kraków }\end{array}$ \\
\hline Hypermarket & Krasne & $\begin{array}{c}\text { Zakopane } \\
\text { Oświęcim }\end{array}$ & $\begin{array}{c}\text { Nowy Sącz } \\
\text { Stalowa Wola }\end{array}$ & $\begin{array}{c}\text { Tarnów } \\
\text { Rzeszów }\end{array}$ & $\begin{array}{c}\text { Kraków } \\
\text { Kraków }\end{array}$ \\
\hline Petrol Station & $\begin{array}{c}\text { Wieliczka } \\
\text { Wadowice }\end{array}$ & $\begin{array}{c}\text { Zakopane } \\
\text { Oświęcim }\end{array}$ & Przemyśl & Rzeszów & $\begin{array}{c}\text { Kraków } \\
\text { Kraków }\end{array}$ \\
\hline Shop & $\begin{array}{c}\text { Kęty } \\
\text { Chełmek }\end{array}$ & $\begin{array}{c}\text { Nowy Targ } \\
\text { Dębica }\end{array}$ & - & $\begin{array}{c}\text { Rzeszów } \\
\text { Rzeszów }\end{array}$ & $\begin{array}{c}\text { Kraków } \\
\text { Kraków }\end{array}$ \\
\hline Shopping Center & Niepołomice & $\begin{array}{c}\text { Olkusz } \\
\text { Dębica }\end{array}$ & $\begin{array}{c}\text { Nowy Sącz } \\
\text { Mielec }\end{array}$ & $\begin{array}{c}\text { Tarnów } \\
\text { Rzeszów }\end{array}$ & $\begin{array}{l}\text { Kraków } \\
\text { Kraków }\end{array}$ \\
\hline
\end{tabular}

Source: Own elaboration

\section{Methodology}

In order to establish the distribution of withdrawals from ATMs throughout the day, the Kolmogorov-Smirnov Goodness-of-Fit Test (K-S test) is a nonparametric test for the equality of continuous, one-dimensional probability distributions that can be used to compare a sample with a reference probability distribution (one-sample K-S test), or to compare two samples (two-sample K-S test). The Kolmogorov-Smirnov statistic quantifies a distance between the empirical distribution function of the sample and the cumulative distribution function of the reference distribution, or between the empirical distribution functions of two samples. The K-S-test has the advantage of making no assumption about the distribution of data; i.e., it is non-parametric and distribution-free. In the first version, the null hypothesis (H0) states that both distributions are identical.

One should remember that the Kolmogorov-Smirnov test is based on the Central Limit Theorem and, thus, it can only be used if the sample size is large enough (at least several dozen). Clustering observations in the intervals may lead to misleading conclusions; however, in practice, the examined values are observed only with a certain level of accuracy, which is associated with the assumed system of units. This, in turn, inevitably leads to the process of grouping the 
observations. The ranges of the intervals should not exceed the scale considered for a particular process. In this paper, empirical distributions have been created on the basis of 15-minute data. Depending on the starting time of the ATM, the first interval covered the period from the midnight to 8.00 or $10.00 \mathrm{am}$, and the last interval covered the period from 8.00 or $10.00 \mathrm{pm}$ to midnight.

From a practical point of view, this approach seems to be sufficient, as the accuracy of determining the time of arrival of the loading convoy is equal to approximately 15-30 minutes (due to traffic jams).

\section{The results of the Kolmogorov-Smirnov Goodness-of-Fit Test}

The research on the similarity of the distribution of withdrawals throughout the day was carried out in several different aspects. The first part of the study was devoted to checking whether the structures of withdrawals from each of the ATMs on different days of the year are similar. The second part of the research was devoted to verifying whether withdrawals throughout the same days are characterized by similar distributions for different ATMs. In addition, the presentation of the empirical results takes into account the location of the ATMs.

\subsection{The results of Two Sample Goodness-of-Fit Test of withdrawals in particular days of the year}

We tested whether the distribution of withdrawals throughout the day from each ATM is similar for different days of the year. The research was performed pairwise. Figures 1 and 2 illustrate exemplary empirical distributions of the time of withdrawals obtained for few days of the year for two randomly selected ATMs. The first ATM is located in a shopping center in Kraków, and the second one is located in a hypermarket in Rzeszów.

A visual inspection of the figure presented above provides a basis to claim that the shapes of the empirical distributions for all selected days are quite similar; nevertheless, the fact that the data comes from different periods of the year and describes withdrawals made on different days of the week. Only in the case of withdrawals from ATM2 (realized on $5^{\text {th }}$ of August) did distribution throughout the day differ significantly in comparison to the other days. The shape of the distribution of withdrawals is a bit surprising. In the case of ATM 1, distribution of the time of withdrawals seems to be close to uniform distribution, while logistic distribution also seems to be the proper one for ATM 2 . 
The effect of location on the distribution of withdrawals from selected ATMs...

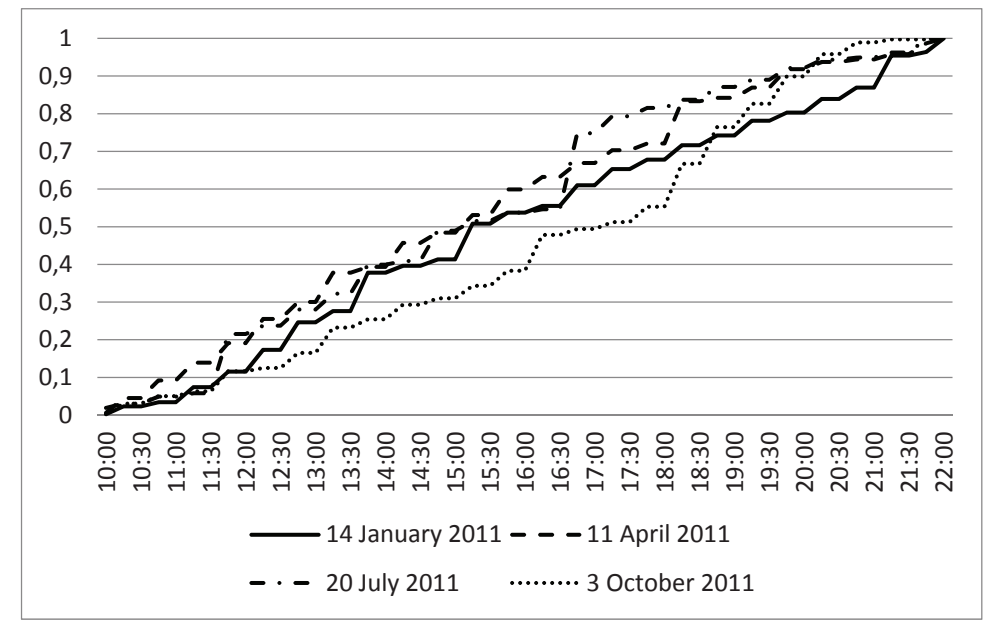

Figure 1. Empirical distribution of withdrawals throughout the day obtained for ATM 1 in four selected days

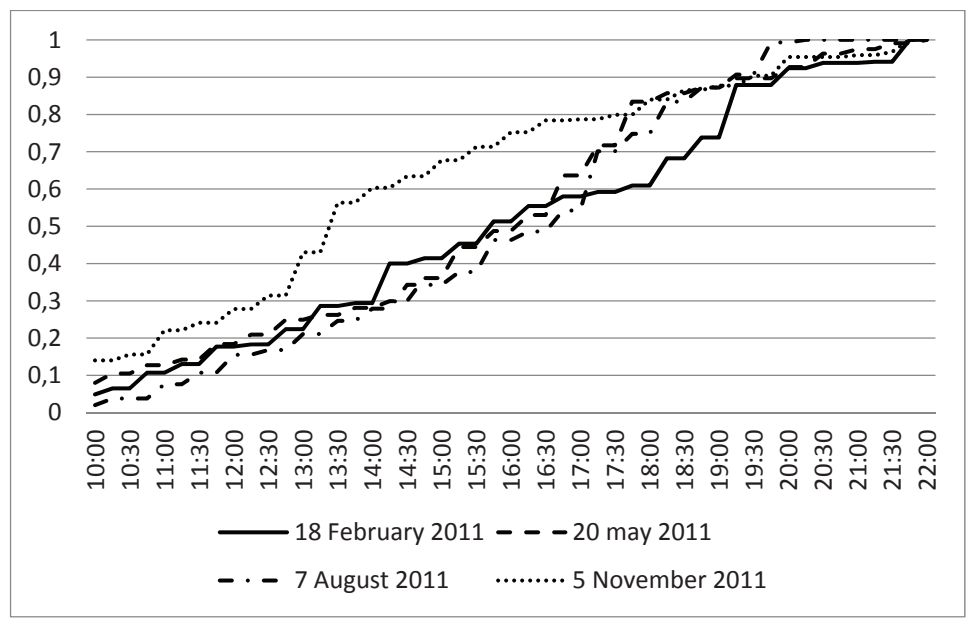

Figure 2. Empirical distribution of withdrawals throughout the day obtained for ATM 2 in four selected days

Table 2 provides information on the share of cases in which the KolmogorovSmirnov test did not reject the null hypothesis that distributions of the time of withdrawals for a pair of analyzed days are the same ${ }^{1}$. We have provided

1 Significance level: $5 \%$ 
statistics for all ATMs as well as average values for each examined type of location (see Tab. 3).

Table 2

Overall statistics of the Kolmogorov-Smirnov test

\begin{tabular}{|c|c|c|c|}
\hline Mean & Standard deviation & Minimum & Maximum \\
\hline $43.75 \%$ & $24.3 \%$ & $18.5 \%$ & $79.5 \%$ \\
\hline
\end{tabular}

Source: Own elaboration

Table 3

Statistics of the Kolmogorov-Smirnov test with respect to the population category and the type of location

\begin{tabular}{|c|c|c|c|c|c|c|}
\hline Type of location & I & II & III & IV & V & Total \\
\hline Bank Branch & $45.5 \%$ & $31.2 \%$ & $27.2 \%$ & $18.7 \%$ & $21.2 \%$ & $31.3 \%$ \\
\hline Hypermarket & $65.7 \%$ & $63.2 \%$ & $56.8 \%$ & $47.1 \%$ & $50.2 \%$ & $56.6 \%$ \\
\hline Petrol Station & $42.1 \%$ & $27.0 \%$ & $29.2 \%$ & $22.7 \%$ & $19.9 \%$ & $28.2 \%$ \\
\hline Shop & $69.3 \%$ & $71.0 \%$ & $55.9 \%$ & $58.3 \%$ & $49.2 \%$ & $60.74 \%$ \\
\hline Shopping Center & $47.2 \%$ & $49.7 \%$ & $41.7 \%$ & $38.6 \%$ & $32.4 \%$ & $41.9 \%$ \\
\hline Total & $54.0 \%$ & $48.4 \%$ & $42.16 \%$ & $37.1 \%$ & $34.6 \%$ & $43.75 \%$ \\
\hline
\end{tabular}

Source: Own elaboration

The results indicate that the significant distribution fitting for withdrawals takes place in around $43.8 \%$ days of the year (for each ATM separately). This result is not good enough, however, to be used in practice. On the other hand, some regularities in the case of the distribution of withdrawals realized in ATMs in different types of locations should be underlined. Withdrawals from ATMs located in hypermarkets and shops are characterized by essentially better distribution fitting in comparison to other locations. Also, ATMs located in smaller towns/ villages exhibit a better fitting of daily withdrawals.

Since the results of the performed analysis did not lead to the expected results, in the next step, we examined whether the desired properties are characteristic features of the particular days of the week. We tested distribution fitting of withdrawals from various ATMs for each day of the week.

The results of this analysis are shown in Table 4 . Figures 3 and 4 present the empirical distributions obtained for ATM 1 and ATM 2 on the same days of the week in different seasons of the calendar year. In the case of ATM 1, withdrawals were realized on Wednesdays, while for ATM 2 - on Fridays. 
The effect of location on the distribution of withdrawals from selected ATMs...

Table 4

Statistics of the Kolmogorov-Smirnov test with respect to the days of the wee

\begin{tabular}{|c|c|c|c|c|c|c|c|}
\hline Day of the week & Mo & Tu & We & Th & Fr & Sa & Su \\
\hline Mean equality & $78.9 \%$ & $85.4 \%$ & $91.2 \%$ & $87.4 \%$ & $81.3 \%$ & $80.2 \%$ & $79.4 \%$ \\
\hline Standard deviation equality & $13.2 \%$ & $12.8 \%$ & $14.3 \%$ & $7.9 \%$ & $10.5 \%$ & $14.3 \%$ & $13.7 \%$ \\
\hline Minimum & $65 . \%$ & $76.2 \%$ & $78.3 \%$ & $75.4 \%$ & $69.5 \%$ & $63.2 \%$ & $62.1 \%$ \\
\hline Maximum & $93.7 \%$ & $95.8 \%$ & $98.2 \%$ & $92.1 \%$ & $89.3 \%$ & $82.7 \%$ & $90.1 \%$ \\
\hline
\end{tabular}

Source: Own elaboration

The results show that, for each day of the week, distribution fitting is relatively good and is close to $80-90 \%$. This observation supports Conjecture 1 . This result can be considered as satisfying. A lack of fit in the case of some days of the year may be a consequence of calendar effects; i.e., days in summer are longer, therefore the length of the withdrawal period is also longer. In the winter, people rarely go out in the evenings. Moreover, if we restrict the analysis only to the distribution of withdrawals on the same days of the week in one month good fitting takes place in over $90 \%$ of the pairs of days.

The results for particular types of location are similar to the general case presented in Table 3.

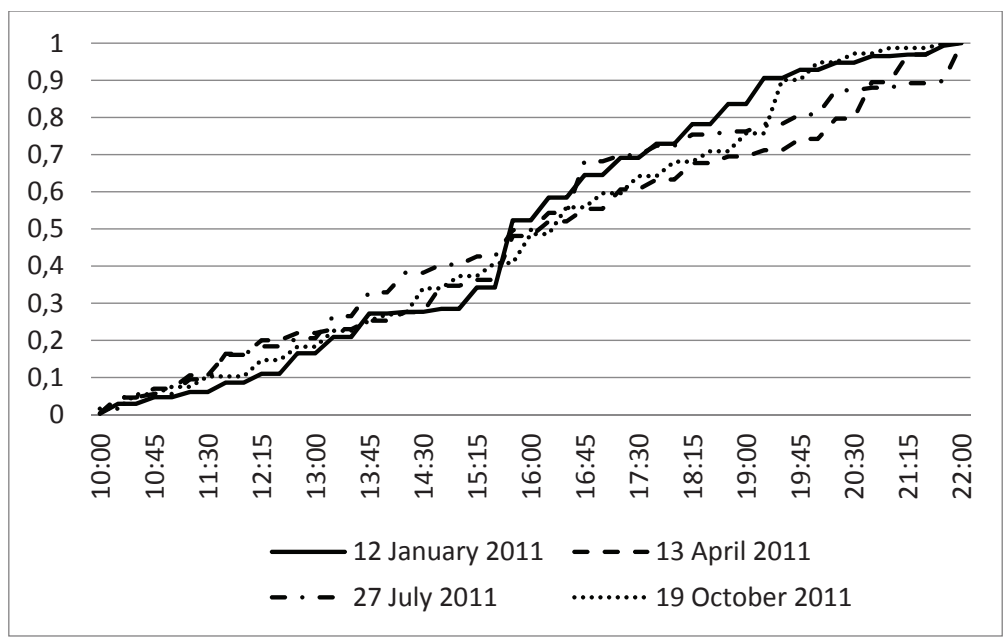

Figure 3. Empirical distribution of withdrawals realized on four selected Wednesdays in the case of ATM 1 


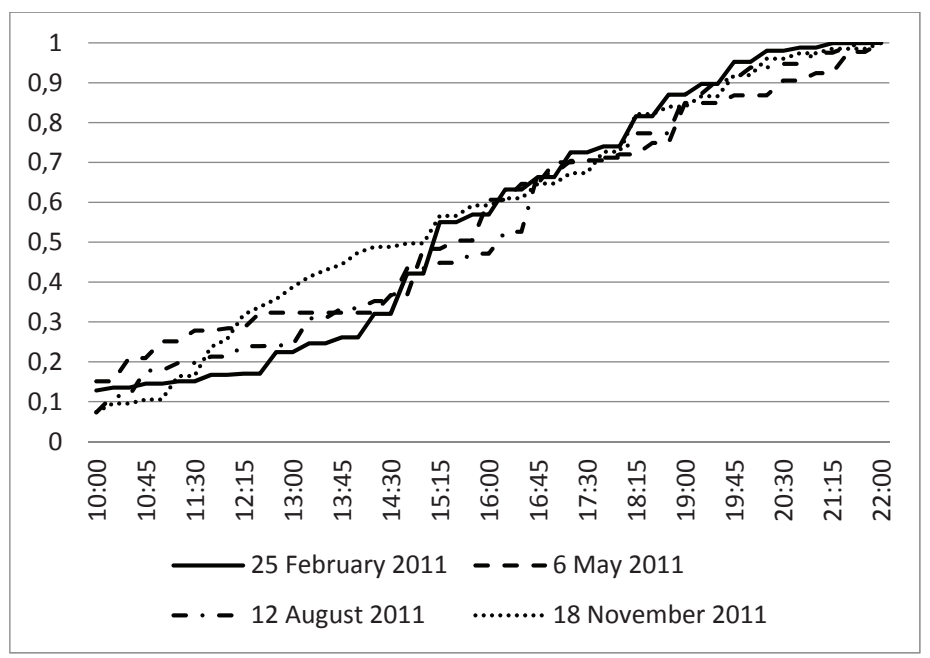

Figure 4. Empirical distribution of withdrawals realized on four selected Fridays in the case of ATM 2

\subsection{The results of Two Sample Goodness-of-Fit Test of withdrawals in the case of different ATMs}

Distribution fitting of withdrawals from an ATM on particular days of the week is a valuable property. However, for a large number of ATMs, this would require evaluation of a separate model for each ATM and for each day of the week. Thus, a practical application of this feature would be difficult.

Therefore, the next part of the analysis should give the answer to the question of whether one can find the discussed relationship between withdrawals from different ATMs realized on the same day. Table 5 provides basic statistics about the percentage shares of those pairs of ATMs for which the Kolmogorov-Smirnov test did not reject the hypothesis of the same distribution of withdrawals on the same day of the year.

Table 5

Percentage results of the distribution fitting test of withdrawals from ATMs on the same days of the year

\begin{tabular}{|c|c|c|c|}
\hline Mean & Standard deviation & Minimum & Maximum \\
\hline $45.7 \%$ & $21.3 \%$ & $23.5 \%$ & $79.5 \%$ \\
\hline
\end{tabular}

Source: Own elaboration 
The effect of location on the distribution of withdrawals from selected ATMs...

The results indicate that, in the case of around $45.7 \%$ of pairs of days, a significant equality of distributions was reached. This result is not satisfactory for practical use. However, when the analysis was restricted solely to ATMs operating at the same types of location, the percentage of distribution fitting significantly increased. Table 6 shows the results obtained for ATMs operating at the same location and for ATMs operating in cities/town/villages of similar population.

These results are in line with Conjecture 2.

Table 6

Percentage results of the distribution fitting test of withdrawals from ATMs with respect to the population category and the type of location

\begin{tabular}{|c|c|c|c|c|c|c|}
\hline Type of location & I & II & III & IV & V & Total \\
\hline Bank Branch & $93.5 \%$ & $90.2 \%$ & $92.3 \%$ & $89.4 \%$ & $91.5 \%$ & $87.4 \%$ \\
\hline Hypermarket & $97.4 \%$ & $95.1 \%$ & $92.8 \%$ & $90.3 \%$ & $92.9 \%$ & $90.3 \%$ \\
\hline Petrol Station & $87.4 \%$ & $85.2 \%$ & $89.1 \%$ & $88.4 \%$ & $86.3 \%$ & $86.3 \%$ \\
\hline Shop & $95.7 \%$ & $92.7 .0 \%$ & $91.9 \%$ & $92.7 \%$ & $90.6 .2 \%$ & $89.7 \%$ \\
\hline Shopping Center & $96.3 \%$ & $94.7 \%$ & $92.3 \%$ & $90.5 \%$ & $91.8 \%$ & $88.4 \%$ \\
\hline Total & $83.6 \%$ & $88.4 \%$ & $79.4 \%$ & $80.3 \%$ & $77.6 \%$ & $38.7 \%$ \\
\hline
\end{tabular}

Source: Own elaboration

In Table 6, one can see that the distribution of time of withdrawals from ATMs operating at the same location (or towns of similar population) are the same in more than $85 \%$ (the best distribution fitting for ATMs in hypermarkets -90.3\%; the lowest for petrol stations - 86.3\%). In the case of ATMs operating in the same types of cities/towns/villages, the results are slightly lower (around 77.6\%-88.4\%).

The results of empirical research indicated that the distribution of the time of withdrawals from ATMs throughout the day are similar as in the case of the ATMs operating in the same type of location and on the same days of the week. This conclusion is confirmed by the results of the analysis presented in Table 7.

In addition, the plots of empirical distribution of withdrawals from four different ATMs operating in shopping centers in Małopolska and Podkarpacie Provinces on four different Mondays during the year 2011 are presented in Figure 5. 
Table 7

Percentage results of the distribution fitting test of withdrawals from ATMs on the same days of the week with respect to the type of location

\begin{tabular}{|c|c|c|c|c|c|c|c|}
\hline Type of location & Mo & Tu & We & Th & Fr & Sa & Su \\
\hline Bank Branch & $86.5 \%$ & $98.2 \%$ & $91.5 \%$ & $90.4 \%$ & $92.3 \%$ & $91.4 \%$ & $88.5 \%$ \\
\hline Hypermarket & $91.4 \%$ & $93.4 \%$ & $90.8 \%$ & $92.7 \%$ & $89.9 \%$ & $91.4 \%$ & $93.1 \%$ \\
\hline Petrol Station & $88.2 \%$ & $76.4 \%$ & $85.2 \%$ & $84.2 \%$ & $75.4 \%$ & $82.3 \%$ & $83.7 \%$ \\
\hline Shop & $89.7 \%$ & $88.2 \%$ & $93.7 \%$ & $91.3 \%$ & $94.6 \%$ & $92.3 \%$ & $91.6 \%$ \\
\hline Shopping Center & $90.1 \%$ & $87.7 \%$ & $91.5 \%$ & $90.9 \%$ & $92.8 \%$ & $91.4 \%$ & $\mathbf{8 7 . 6 \%}$ \\
\hline
\end{tabular}

Source: Own elaboration

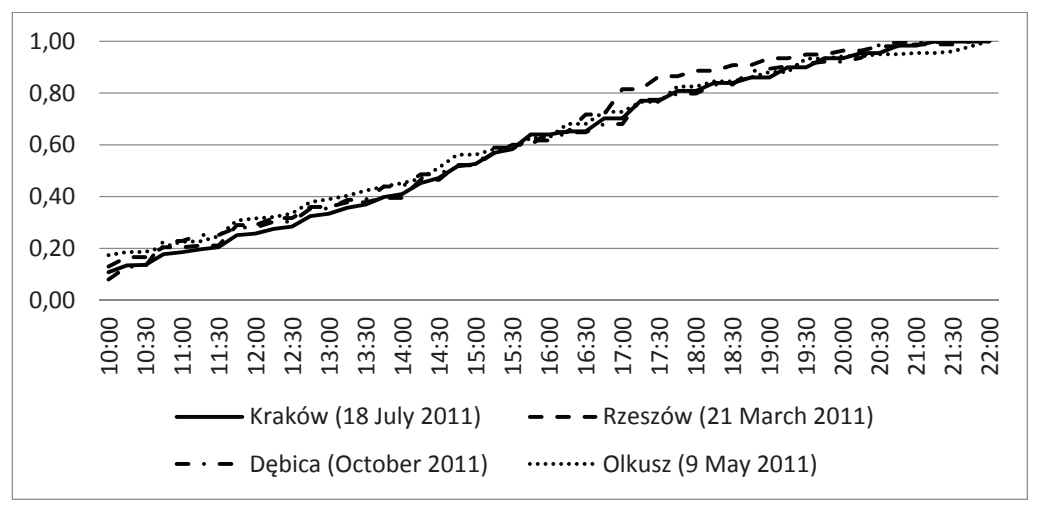

Figure 5. Empirical distributions obtained for four ATMs operating in shopping centers

One can see a relatively high similarity of distribution presented in Figure 5. However, one may also observe an outlier around 5 pm (in the case of the distribution of withdrawals realized in Rzeszów).

\subsection{Distribution fitting (one sample Goodness-of-Fit Test)}

The analysis of the similarity of distribution of withdrawals from ATMs operating in the same types of locations and on the same days of the week provides a basis to search for theoretical distributions which would efficiently describe the structure of cash withdrawals from ATMs. In addition, the results of Kolmogorov-Smirnov indicate that both types of distribution fit the empirical data well. Thus, on the basis of the empirical results, we may claim that, for all ATMs, one should focus on no more 
The effect of location on the distribution of withdrawals from selected ATMs...

than 35 different theoretical distributions. This can provide a useful description of the structure of withdrawals throughout every day of the year for all ATMs.

The shape of the empirical distributions presented in Figs 1-5 suggests that logistic distribution or uniform distribution would be appropriate to describe the structure under study. However, for the sake of comprehensiveness, other types of distribution were also taken into account; i.e., normal, Laplace, Weibull, and gamma distribution. The choice of such distributions was a consequence of the fact that these distributions seem to have appropriate shapes. Moreover, they are characterized by a relatively low number of parameters (required to be estimated), which is especially important for practical applications.

In order to test the usefulness of the theoretical distributions in describing the structure of withdrawals from ATMs throughout the day, we used the Kolmogorov-Smirnov test.

Table 8 presents the data on the percentage shares of the days of the week (in specific types of locations) in which the values of the Kolmogorov-Smirnov statistic were the lowest for each selected distribution. For each type of location, the two best distributions (according to the values of test statistics) were chosen.

Table 8

The results of fitting theoretical distributions

\begin{tabular}{|c|c|c|c|c|c|c|c|}
\hline $\begin{array}{r}\text { Type of } \\
\text { location }\end{array}$ & Mo & Tu & We & Th & Fr & Sa & Su \\
\hline \multirow{2}{*}{$\begin{array}{c}\text { Bank } \\
\text { Branch }\end{array}$} & $\begin{array}{l}\text { Logistic } \\
(66.2 \%)\end{array}$ & $\begin{array}{l}\text { Logistic } \\
(70.2 \%)\end{array}$ & $\begin{array}{c}\text { Uniform } \\
(44.5 \%)\end{array}$ & $\begin{array}{l}\text { Logistic } \\
(79.2 \%)\end{array}$ & $\begin{array}{l}\text { Logistic } \\
\text { (80.1\%) }\end{array}$ & $\begin{array}{l}\text { Logistic } \\
(84.5 \%)\end{array}$ & $\begin{array}{l}\text { Logistic } \\
(67.4 \%)\end{array}$ \\
\hline & $\begin{array}{l}\text { Uniform } \\
(24.4 \%)\end{array}$ & $\begin{array}{l}\text { Uniform } \\
(20.4 \%)\end{array}$ & $\begin{array}{l}\text { Uniform } \\
\text { (42.5\%) }\end{array}$ & $\begin{array}{l}\text { Uniform } \\
\text { (14.3\%) }\end{array}$ & $\begin{array}{l}\text { Uniform } \\
\text { (10.2\%) }\end{array}$ & $\begin{array}{c}\text { Laplace'a } \\
\text { (9.4\%) }\end{array}$ & $\begin{array}{l}\text { Uniform } \\
\text { (23.4\%) }\end{array}$ \\
\hline \multirow{2}{*}{$\begin{array}{l}\text { Hyper- } \\
\text { market }\end{array}$} & $\begin{array}{l}\text { Logistic } \\
(79.4 \%)\end{array}$ & $\begin{array}{l}\text { Logistic } \\
(85.2 \%)\end{array}$ & $\begin{array}{c}\text { Uniform } \\
\text { (90.5\%) }\end{array}$ & $\begin{array}{l}\text { Logistic } \\
\text { (79.2\%) }\end{array}$ & $\begin{array}{l}\text { Logistic } \\
(86.3 \%)\end{array}$ & $\begin{array}{l}\text { Logistic } \\
\text { (84.5\%) }\end{array}$ & $\begin{array}{l}\text { Logistic } \\
\text { (76.4\%) }\end{array}$ \\
\hline & $\begin{array}{c}\text { Uniform } \\
(17.6 \%)\end{array}$ & $\begin{array}{c}\text { Laplace'a } \\
(7.4 \%)\end{array}$ & $\begin{array}{c}\text { Uniform } \\
\text { (7.5\%) }\end{array}$ & $\begin{array}{l}\text { Uniform } \\
(14.3 \%)\end{array}$ & $\begin{array}{l}\text { Uniform } \\
(12.4 \%)\end{array}$ & $\begin{array}{c}\text { Laplace'a } \\
(9.4 \%)\end{array}$ & $\begin{array}{l}\text { Uniform } \\
\text { (19.2\%) }\end{array}$ \\
\hline \multirow{2}{*}{$\begin{array}{l}\text { Petrol } \\
\text { Station }\end{array}$} & $\begin{array}{l}\text { Uniform } \\
\text { (63.4\%) }\end{array}$ & $\begin{array}{l}\text { Uniform } \\
(71.2 \%)\end{array}$ & $\begin{array}{l}\text { Logistic } \\
(50.4 \%)\end{array}$ & $\begin{array}{l}\text { Uniform } \\
(68.3 \%)\end{array}$ & $\begin{array}{l}\text { Uniform } \\
\text { (72.9\%) }\end{array}$ & $\begin{array}{l}\text { Uniform } \\
(64.7 \%)\end{array}$ & $\begin{array}{l}\text { Uniform } \\
\text { (32.4\%) }\end{array}$ \\
\hline & $\begin{array}{l}\text { Logistic } \\
\text { (27.6\%) }\end{array}$ & $\begin{array}{l}\text { Logistic } \\
(25.5 \%)\end{array}$ & $\begin{array}{c}\text { Uniform } \\
\text { (45.2\%) }\end{array}$ & $\begin{array}{l}\text { Logistic } \\
(27.7 \%)\end{array}$ & $\begin{array}{l}\text { Logistic } \\
(26.5 \%)\end{array}$ & $\begin{array}{l}\text { Logistic } \\
(42.2 \%)\end{array}$ & $\begin{array}{l}\text { Logistic } \\
\text { (56.2\%) }\end{array}$ \\
\hline \multirow{2}{*}{ Shop } & $\begin{array}{l}\text { Logistic } \\
(69.6 \%)\end{array}$ & $\begin{array}{l}\text { Logistic } \\
(55.7 \%)\end{array}$ & $\begin{array}{c}\text { Uniform } \\
\text { (79.5\%) }\end{array}$ & $\begin{array}{l}\text { Logistic } \\
(84.2 \%)\end{array}$ & $\begin{array}{l}\text { Logistic } \\
(80.2 \%)\end{array}$ & $\begin{array}{l}\text { Logistic } \\
(74.5 \%)\end{array}$ & $\begin{array}{l}\text { Logistic } \\
(69.4 \%)\end{array}$ \\
\hline & $\begin{array}{l}\text { Uniform } \\
\text { (28.6\%) }\end{array}$ & $\begin{array}{l}\text { Laplace } \\
\text { (40.9\%) }\end{array}$ & $\begin{array}{l}\text { Logistic } \\
\text { (18.4\%) }\end{array}$ & $\begin{array}{l}\text { Laplace } \\
(8.3 \%)\end{array}$ & $\begin{array}{l}\text { Uniform } \\
\text { (15.4\%) }\end{array}$ & $\begin{array}{l}\text { Uniform } \\
\text { (23.7\%) }\end{array}$ & $\begin{array}{l}\text { Uniform } \\
\text { (25.0\%) }\end{array}$ \\
\hline \multirow{3}{*}{$\begin{array}{l}\text { Shop- } \\
\text { ping } \\
\text { Center }\end{array}$} & $\begin{array}{l}\text { Logistic } \\
\text { (89.4\%) }\end{array}$ & $\begin{array}{l}\text { Logistic } \\
(80.3 \%)\end{array}$ & $\begin{array}{l}\text { Logistic } \\
(90.5 \%)\end{array}$ & $\begin{array}{l}\text { Logistic } \\
(87.0 \%)\end{array}$ & $\begin{array}{l}\text { Logistic } \\
\text { (86.3\%) }\end{array}$ & $\begin{array}{l}\text { Logistic } \\
(79.5 \%)\end{array}$ & $\begin{array}{l}\text { Logistic } \\
80.7 \%)\end{array}$ \\
\hline & Uniform & Laplace'a & Uniform & Uniform & Uniform & Laplace'a & Uniform \\
\hline & & & & & & & \\
\hline
\end{tabular}

Source: Own elaboration 
This analysis shows that, from the set of theoretical distributions, the logistic distribution fits the data best. In the case of four out of five examined types of locations, this distribution describes their structure in the best way. It should be noted that, in the case of ATMs operating in petrol stations, the uniform distribution fits the data better than the logistic one. The findings in this section support Conjectures 3 and 4 .

\subsection{The results of the parameters estimation of the distribution of withdrawals with respect to the groups of ATMs}

The results of the empirical analysis of distribution fitting provide a basis for building one single model that would be suitable for the whole group of ATMs. This model will be based on logistic and uniform distributions. In the case of uniform distribution, the estimation of parameters for the whole group of ATMs that operate at certain hours is rather trivial. For logistic distribution, one should determine one pair of the parameters so the obtained logistic distribution best fits the corresponding withdrawals throughout the day.

In order to estimate the parameters, the panel ordinary least squares (POLS) approach was applied. On the basis of the data from the chosen day of the week and the chosen type of location, the parameters were estimated via POLS. This way, we have gained 35 different logistic distribution functions.

Next, in order to verify the results of the performed analyses, a GoodnessOf-Fit-Test of the obtained "universal" distribution with empirical distribution was performed. Table 9 presents data on the percentage share of the days for which the Kolmogorov-Smirnov test provides no evidence for rejecting the null hypothesis of logistic distribution. In addition, the Table shows the results of the estimation of the parameters of distribution $F(x)=\frac{1}{1+e^{-(x-\mu) / s}}$.

Table 9

The results of the one sample K-S test performed for logistic distribution and empirical distributions

\begin{tabular}{|c|c|c|c|c|c|c|c|}
\hline $\begin{array}{r}\text { Type of } \\
\text { location }\end{array}$ & Mo & $\mathbf{T u}$ & We & Th & Fr & Sa & Su \\
\hline $\begin{array}{c}\text { Bank } \\
\text { Branch }\end{array}$ & $\begin{array}{c}72.5 \% \\
\mu=246.9 \\
s=162.1\end{array}$ & $\begin{array}{c}75.2 \% \\
\mu=273.3 \\
s=105.9\end{array}$ & $\begin{array}{c}79.5 \% \\
\mu=177.3 \\
s=122.3\end{array}$ & $\begin{array}{c}81.4 \% \\
\mu=236.1 \\
s=106.3\end{array}$ & $\begin{array}{c}69.3 \% \\
\mu=171.4 \\
s=93.3\end{array}$ & $\begin{array}{c}70.0 \% \\
\mu=115.3 \\
s=201.7\end{array}$ & $\begin{array}{c}68.5 \% \\
\mu=329.1 \\
s=165.6\end{array}$ \\
\hline $\begin{array}{l}\text { Hyper- } \\
\text { market }\end{array}$ & $\begin{array}{c}75.4 \% \\
\mu=249.2 \\
s=194.9\end{array}$ & $\begin{array}{c}73.2 \% \\
\mu=192.1 \\
s=151.2\end{array}$ & $\begin{array}{c}79.8 \% \\
\mu=278.0 \\
s=151.2\end{array}$ & $\begin{array}{c}80.1 \% \\
\mu=246.8 \\
s=163.1\end{array}$ & $\begin{array}{c}75.3 \% \\
\mu=197.9 \\
\mathrm{~s}=156.0\end{array}$ & $\begin{array}{c}79.2 \% \\
\mu=236.6 \\
s=152.9\end{array}$ & $\begin{array}{c}71.7 \% \\
\mu=194.7 \\
s=154.1\end{array}$ \\
\hline
\end{tabular}


The effect of location on the distribution of withdrawals from selected ATMs...

Table 9 cont.

\begin{tabular}{|c|c|c|c|c|c|c|c|}
\hline $\begin{array}{c}\text { Petrol } \\
\text { Station }\end{array}$ & $\begin{array}{c}43.2 \% \\
\mu=224.5 \\
s=205.4\end{array}$ & $\begin{array}{c}39.8 \% \\
\mu=184.1 \\
s=169.2\end{array}$ & $\begin{array}{c}45.1 \% \\
\mu=194.2 \\
s=139.6\end{array}$ & $\begin{array}{c}38.2 \% \\
\mu=271.6 \\
s=185.2\end{array}$ & $\begin{array}{c}40.7 \% \\
\mu=180.4 \\
s=191.1\end{array}$ & $\begin{array}{c}36.3 \% \\
\mu=59.4 \\
s=170.8\end{array}$ & $\begin{array}{c}40.5 \% \\
\mu=246.5 \\
s=135.9\end{array}$ \\
\hline Shop & $\begin{array}{c}77.7 \% \\
\mu=160.7 \\
s=170.8\end{array}$ & $\begin{array}{c}81.3 \% \\
\mu=181.6 \\
\mathrm{~s}=158.3\end{array}$ & $\begin{array}{r}70.5 .7 \% \\
\mu=244.9 \\
s=163.2\end{array}$ & $\begin{array}{c}74.3 \% \\
\mu=160.0 \\
s=152.9\end{array}$ & $\begin{array}{c}69.8 .6 \% \\
\mu=139.0 \\
s=160.9\end{array}$ & $\begin{array}{c}77.3 \% \\
\mu=105.5 \\
s=160.6\end{array}$ & $\begin{array}{c}72.6 \% \\
\mu=350.6 \\
\mathrm{~s}=163.4\end{array}$ \\
\hline $\begin{array}{l}\text { Shopping } \\
\text { Center }\end{array}$ & $\begin{array}{c}80.1 \% \\
\mu=238.2 \\
s=151.3\end{array}$ & $\begin{array}{c}77.7 \% \\
\mu=196.3 \\
s=154.8\end{array}$ & $\begin{array}{c}81.5 \% \\
\mu=255.1 \\
s=156.6\end{array}$ & $\begin{array}{c}80.9 \% \\
\mu=258.0 \\
s=144.2\end{array}$ & $\begin{array}{c}72.8 \% \\
\mu=261.3 \\
s=140.6\end{array}$ & $\begin{array}{c}71.4 \% \\
\mu=135.9 \\
\mathrm{~s}=136.5\end{array}$ & $\begin{array}{c}78.6 \% \\
\mu=243.9 \\
s=163.6\end{array}$ \\
\hline
\end{tabular}

Source: Own elaboration

Figure 6 presents the joint plots of empirical distributions taken from Figure 5 and fitted logistic distribution.

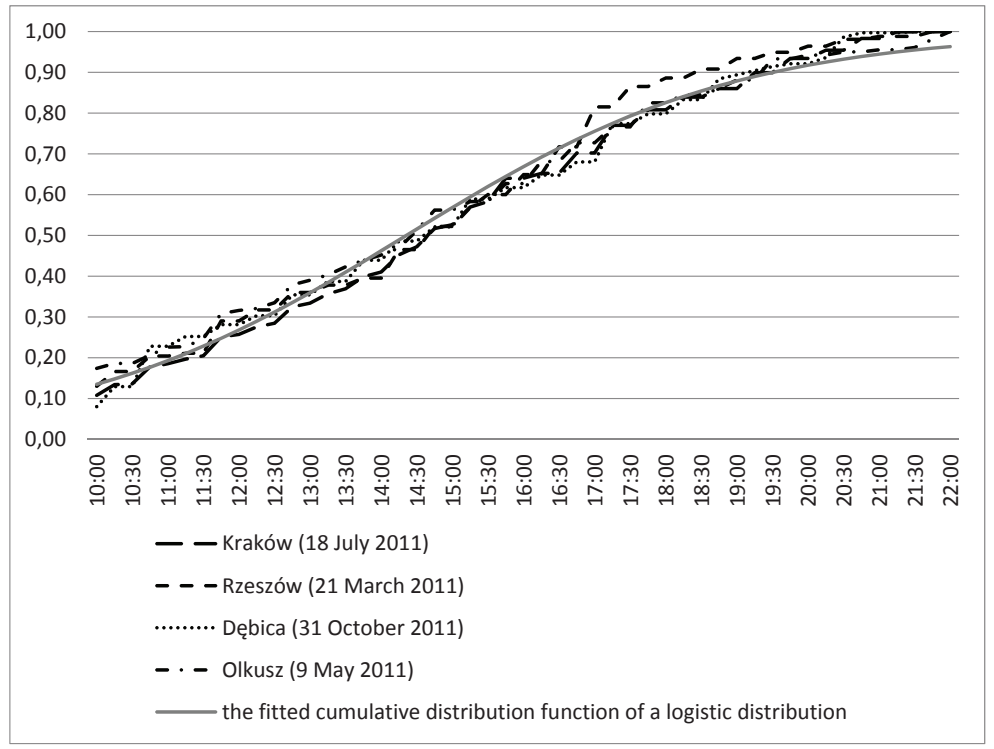

Figure 6. The results of fitting logistic distribution to selected empirical distribution

The results confirm the correctness of the performed analyses. One may note that, in the case of ATMs operating at petrol stations, using logistic distribution to describe the structure of withdrawals may not be appropriate. In this case, we suggest the application of uniform distribution. For other types 
of locations, logistic distribution is suitable to describe the structure of withdrawals throughout the day. These findings were also confirmed by the plots presented in Figure 6.

\section{Conclusions}

From a practical point of view, knowledge of the structure of cash withdrawals throughout the day may be of high importance in the process of managing an ATM network. The owner or operator of an ATM network may use the information about distribution of withdrawals to optimize the process of reloading the cash into ATMs.

The results presented in this paper show that the structures of withdrawals are similar among the examined ATMs owned by the Euronet company. The similarity of the distribution of withdrawals turned out to be high, especially for ATMs operating in the same types of locations under the restriction of focusing on the same days of the week. In addition, logistic distribution was found to best fit withdrawals from ATMs operating in shopping centers, bank branches, shops, and hypermarkets. However, uniform distribution was found to be superior in describing the structure of withdrawals from ATMs operating at gas stations.

In the paper the group of 35 models, which can be used to predict the size of withdrawals from ATMs in the particular days of the week, was evaluated. The applicability of these results, however, is determined by an ability to construct proper forecasts of daily withdrawals from an ATM.

\section{Reference}

[1] Adams A.S., Thiehen K.A. 1991, Automatic teller machines and the older population, "Applied Ergonomics", vol. 22, pp. 85-90.

[2] Amromin E., Chakravorti S. 2007, Debit card and cash usage: a crosscountry analysis, Technical report, Federal Reserve Bank of Chicago.

[3] Boeschoten W.C. 1998, Cash management, payment patterns and the demand for money, "De Economist", vol. 146, pp. 117-42.

[4] Brentnall A.R., Crowder M.J., Hand D.J. 2008, A statistical model for the temporal pattern of individual automated teller machine withdrawals, “Applied Statistics", vol. 57(1), pp. 43-59.

[5] Brentnall A.R., Crowder M.J., Hand D.J. 2010, Predicting the amount individuals withdraw at cash machines using a random effects multinomial model, "Statistical Modelling", vol. 10(2), pp. 197-214. 
The effect of location on the distribution of withdrawals from selected ATMs...

[6] Cleveland W.S., Devlin S.J. 1980, Calendar Effects in Monthly Time Series: Detection by Spectrum Analysis and Grapbical Methods, "Journal of the American Statistical Association”, vol. 371(75), pp. 487-496.

[7] Findley D.F., Monsell B.C. 2009, Modeling Stock Trading Day Effects Under Flow Day-of-Week Effect Constraints, "Journal of Official Statistics", vol. 25(3), pp. 415-430.

[8] Findley D.F., Monsell B.C., Bell W.R., Otto M.C., Chen B.C. 1998, New capabilities and Methods of the X-12-ARIMA seasonal adjustment program, "Journal of Business and Economic Statistics", vol. 16(2), pp. 127-177.

[9] Findley D.F., Soukup R.J. 1999, On the Spectrum Diagnostics Used by X-12-ARIMA to Indicate the Presence of Trading Day Effects after Modeling or Adjustment, "Proceedings of the American Statistical Association, Business and Statistics Section", pp. 144-149.

[10] Findley D.F., Soukup R.J. 2000, Modeling and Model Selection for Moving Holidays, "Proceedings of the American Statistical Association, Business and Economics Statistics Section", pp. 102-07.

[11] Findley D.F., Soukup R.J. 2001, Detection and Modeling of Trading Day Effects, in: ICES II: Proceedings of the Second International Conference on Economic Surveys, pp. 743-753.

[12] Gill J.M. 1996, Making cash dispensers easier to use, http:/www.tiresias. org/research/reports/mcdeu.htm (accessed 8 April 2005).

[13] Gurgul G., Suder M. 2012, Efekt kalendarza wyplat z bankomatów sieci Euronet, "Zeszyty Naukowe Wyższej Szkoły Ekonomii i Informatyki w Krakowie", vol. 8. pp. 25-42.

[14] Gurgul H., Suder M. 2013, Modeling of Withdrawals from Selected ATMs of the „Euronet” Network, "Managerial Ekonomics”, vol. 13, pp. 65-82.

[15] Hand D.J., Blunt G. 2001, Prospecting for gems in credit card data, IMA "Journal of Management Mathematics", vol. 12, pp. 173-200.

[16] Hatta K., Iiyama Y. 1991, Ergonomic study of automatic teller machine operability, "International Journal of Human-Computer Interaction" vol. 3, pp. 295-309.

[17] Johnson G.I., Coventry L. 2001, You talking to me? Exploring voice in self-service user interfaces, "International Journal of Human-Computer Interaction", vol. 13(2), pp. 161-186.

[18] Liu L.M. 1980, Analysis of Time Series with Calendar Effects, "Management Science", vol. 26, pp. 106-112.

[19] McElroy T.S., Holland S. 2005, A Nonparametric Test for Assessing Spectral Peaks, Research Report 2005-10, Statistical Research Division, U.S. Bureau of the Census, Washington D.C.

[20] Mester L. 2009, Changes in the use of electronic means of payment: 1995-2007, "Business Review", issue Q3, pp. 29-37. 
[21] Rogers W., Gilbert D.K., Cabrera E.F. 1997, An analysis of automatic teller machine usage by older adults: A structured interview approach, "Applied Ergonomics", vol. 28, pp. 173-180.

[22] Simutis R., Dilijonas D., Bastina L. 2008, Cash demand forecasting for ATM using Neural Networks and support vector regression algorithms, 20th International Conference, EURO Mini Conference, "Continuous Optimization and Knowledge-Based Technologies” (EurOPT-2008), Selected Papers, Vilnius May 20-23, , pp. 416-421.

[23] Snellman H., Viren M. 2009, ATM networks and cash usage, "Applied Financial Economics", vol. 19 (10), pp. 841-851.

[24] Thatcher A., Shaik F., Zimmerman C. 2005, Attitudes of semiliterate and literate bank account bolders to the use of automatic teller machines, "International Journal of Industrial Ergonomics", vol. 35(2), pp. 115-130.

[25] Van der Heiden G.C. 1990, Thirty-something million: Should they be exceptions?, "Human Factors", vol. 32(4), pp. 383-396. 